\title{
PENGATURAN POSISI CONTROL RODS UNTUK MELANJUTKAN OPERASI HTGR PASCA SCRAM DENGAN SIMULATOR PCTRAN-HTR
}

\author{
M. Khoirul Anam¹, Dwi Priyantoro², Syarip ${ }^{3}$ \\ 1) Sekolah Tinggi Teknologi Nuklir, Yogyakarta, Indonesia, mkhoirulanam@gmail.com \\ 2) Sekolah Tinggi Teknologi Nuklir, Yogyakarta, Indonesia \\ 3) Pusat Sains dan Teknologi Akselerator, Yogyakarta, Indonesia
}

\begin{abstract}
ABSTRAK
PENGATURAN POSISI CONTROL RODS UNTUK MELANJUTKAN OPERASI HTGR PASCA SCRAM DENGAN SIMULATOR PCTRAN-HTR. Reaktivitas pada reaktor HTGR diatur dengan batang kendali (CR) yang terdiri dari 16 pasang yang terbagi menjadi dua bagian, yaitu 7 pasang di tengah teras reaktor dan 9 pasang di bagian tepi moderator. Ketika kondisi abnormal terjadi CR secara otomatis akan jatuh tersisip ke dalam teras reaktor sehingga reaktor SCRAM dan berada pada kondisi subkritis. Untuk melanjutkan operasi reaktor pasca SCRAM diperlukan analisis terkait pengaruh reaktivitas negatif dari Xenon dan suhu. Pada penelitian ini telah berhasil dilakukan simulasi penentuan posisi CR yang optimal menggunakan PCTRAN-HTR untuk melanjutkan operasi reaktor dalam dua tingkat daya, yaitu daya rendah (RDE) dengan daya 10 MWth dan daya tinggi 200 MWth. Kedua tingkat daya tersebut dicapai dengan menarik CR ke posisi tertentu sampai kondisinya kritis lagi. Hasil yang telah diperoleh menunjukkan bahwa dengan posisi CR $52 \%$ naik sudah bisa menghasilkan kondisi superkritis untuk daya RDE dan dengan posisi $57 \%$ dan $58 \%$ naik, untuk daya tinggi sehingga status operasi dari start (S) bisa diganti power (P).
\end{abstract}

Kata kunci: Batang Kendali, HTGR, Reaktivitas, SCRAM

\begin{abstract}
ADJUSTMENT OF CONTROL RODS POSITION TO CONTINUE HTGR OPERATION AFTER REACTOR SCRAM BY USING PCTRAN-HTR SIMULATOR. HTGR have 16 pairs of control rods (CRs) which are 7 pairs located in the central region and 9 pairs located in the outer area of moderator. This CRs are used to control reactivity of the reactor core, and if the abnormal condition is occurred, these control rods automatically dropped to the core or reactor scram and reactor in subcritical condition. To continue reactor operation, the CRs should be withdrawal to achieve reactor in critical condition but before this action, the analysis of negative reactivity effects of Xenon and fuel temperature should be done. The simulation to determine the optimum CRs positions in achieving reactor critical in two reactor power levels operation of $10 \mathrm{MWt}(\mathrm{RDE})$ and $200 \mathrm{MWt}$ has been successfully done by using PCTRAN-HTR simulator. Both power levels conditions are reached by withdrawal the CRs in the certain position. The simulation results show that $52 \%$ up of CRs in RDE can achieve a critical condition while for $200 \mathrm{MWth}$ the critical condition is achieved by $57 \%$ and $58 \%$ up, and the status operation can change from start $(S)$ to power $(P)$.
\end{abstract}

Keyword:HTGR, Control Rods, Reactivity, SCRAM 


\section{PENDAHULUAN}

High Temperature Engineering Test Reactor (HTTR) di Jepang yang berdaya 30 MWth ${ }^{1}$ dan HTR-10 China dengan daya 10 MWth $^{2}$ telah dibuat dengan penelitian dan pengembangannya bertujuan untuk membangun High Temperature Gas-Cooled Reactor (HTGR) dan juga untuk kegunaan pemanfaatan panas nuklir lainnya ${ }^{3}$. Seperti halnya yang sedang diupayakan oleh Badan Tenaga Nuklir Nasional (BATAN) untuk membangun Reaktor Daya Eksperimental (RDE) dengan daya 10 MWth yang sejenis dengan reaktor HTR-10 untuk keperluan produksi listrik, pembuatan hidrogen untuk produksi pupuk dan lain sebagainya. (Nakagawa, 1992) Blok bahan bakar HTGR secara umum terdiri dari batang bahan bakar yang terdiri dari susunan partikel bahan bakar dengan kernel $\mathrm{UO}_{2}$ yang disusun dalam matrik dan terkompaksi menjadi bahan bakar (fuel compact) di dalam moderator graphit.

HTGR adalah reaktor inovatif dengan karakteristik yang menguntungkan dari sisi efek umpan balik reaktifitas negatif (negative reactivity feedback effect) yang membuat reaktor tetap stabil ketika terjadi penarikan batang kendali (CR) secara tak wajar maupun karena kejadian mengancam lainnya ${ }^{4}$.

Selain itu, HTGR juga memiliki keunggulan dari beberapa sisi lainnya seperti sisi ekonomi, keselamatan, infrastruktur, proliferation resistance dan proteksi fisik, lingkungan dan limbah serta memiliki keselamatan bawaan (inherent safety). Keselamatan bawaan tersebut bisa berupa kapasitas panas teras reaktor yang besar sehingga memiliki kemampuan tinggi untuk mengumpulkan panas dan efek umpan balik reaktifitas negatif artinya kemampuan mengurangi reaksi fisi nuklir secara segera ketika terjadi peningkatan suhu teras reaktor yang berlebihan ${ }^{5}$.

Pada pengoperasian HTGR, kestabilan daya bisa dicapai dengan mengatur reaktivitas teras menggunakan $\mathrm{CR}$ (Tachibana, 2004). Pengaturan CR membuat teras reaktor menghasilkan suhu keluaran yang sesuai atau stabil sehingga tingkatan daya juga stabil. CR tersebut dimasukkan (inserted) ke blok bahan bakar atau ditarik (withdrawl) dari blok bahan bakar sesuai dengan tingkat kestabilan suhu maupun daya yang ditentukan.

CR dimasukkan diantaranya karena keaadaan darurat (SCRAM). Sistem SCRAM ini mengandalkan gravitasi sebagai pendorongnya, setelah terjadi hal-hal yang mengancam keselamatan reaktor diantaranya adalah panas berlebihan, daya listrik sistem keamanan itu sendiri tidak stabil atau terjadi kehilangan pasokan daya lisrik sebagaimana yang telah disimulasikan JAEA. Mereka melakukannya dengan cara manual shutdown sebagai simulasi kehilangan pasokan daya listrik (loss of off-site electrical power) dari salah satu kejadian operasi yang diantisipasi (anticipated operational occurences, AOO $)^{6}$.

Hal tersebut tentunya juga harus menjadi perhatian dalam pengembangan RDE di Indonesia mengingat di negara ini juga sering terjadi pemadaman daya listrik baik dalam waktu singkat maupun lama.

Berdasarkan atas penjelasan tersebut, diasumsikan bahwa kehilangan daya listrik terjadi pada sistem CR hanya sementara saja yang mengakibatkan reaktor SCRAM. Kemudian dinyatakan bahwa masalah sudah diatasi dan semua kondisi aman sehingga operasi perlu dilanjutkan. Oleh karena itu pengoptimalan dalam melanjutkan operasi reaktor perlu dilakukan pada kondisi setelah terjadi SCRAM dengan cara mengatur CR, yaitu penarikan harus dilakukan sesuai dengan karakteristik HTGR itu sendiri yang memiliki kapasitas panas teras reaktor yang besar dan di sisi lain juga memiliki efek umpan balik reaktivitas negatif hingga dicapai daya minimal $30 \%$ sehingga status operasi dari start $(\mathrm{S})$ menjadi power $(\mathrm{P})$ yang mana dengan daya $30 \%$ mempu menggerakkan turbin pembangkit listrik.

Selanjutnya dengan penelitian ini, maka harapannya adalah bisa dijadikan acuan untuk pengoperasian reaktor jenis HTGR setelah SCRAM dan ketika kondisi setelah SCRAM bisa didapatkan kembali daya minimal reaktor berdasarkan panas dari keluaran sistem pendingin oleh penarikan CR dengan memperhatikan efek umpan balik reaktivitas teras. 


\section{LANDASAN TEORI}

\section{PCTRAN-HTR}

PCTRAN-HTR adalah perangkat lunak untuk komputer yang dibuat oleh Micro-Simulation Technology dengan tujuan mensimulasikan reaktor temperatur tinggi (High Temperature Reactor). Reaktor yang disimulasikan pada intinya adalah reaktor HTGR yang merupakan reaktor bersuhu tinggi ketika dioperasikan yang didinginkan oleh gas helium. Berikut tampilan PCTRAN yang ditunjukkan pada Gambar 1.

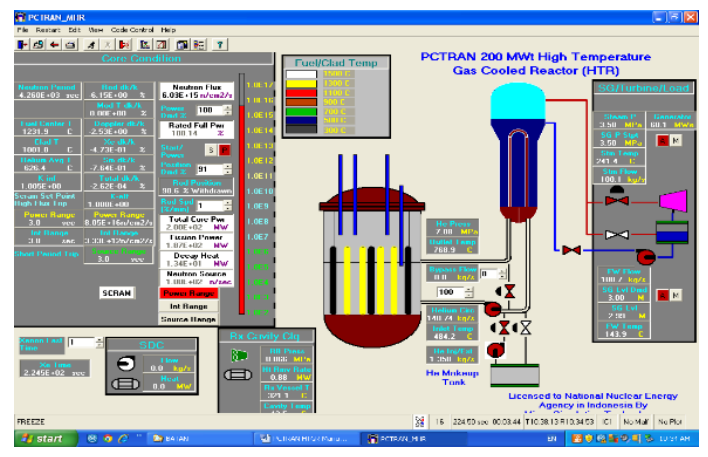

Gambar 1. Tampilan PCTRAN-HTR

PCTRAN-HTR ini memiliki kendali grafik yang menarik pada simulasinya yang menggunakan model sementara kinetika reaktor dan thermal-hidrolik yang sederhana. Pada awal pembuatan simulasi reaktor terbatas hanya pada reaktor berpendingin air.

Kemudian Micro-Simulator Technology mengembangkan sebuah simulasi PCDOS dari reaktor jenis 30MW High Temperatue Test Reactor (HTTR) untuk Japan Atomic Energy Research Institute (JAERI or the current Japan Atomic Energy Agency JAEA) di Oaraii tahun 1998 dan yang sekarang yang pertama kalinya dibuat dengan dasar aplikasi Windows?

Modul dari prototipe HTR ini membangkitkan 200 MWth dengan suhu keluaran pendingin reaktor $800{ }^{\circ} \mathrm{C}$, tekanan sekitar 7 Mpa dengan aliran helium ke teras digerakkan oleh alat sirkulasi dan pengaturan kecepatannya bisa dari 30\%-100\%.

\section{HTGR}

HTGR merupakan reaktor daya generasi IV yang dikembangkan dengan moderator graphit ${ }^{8}$, berbahan bakar berbentuk segienam (prismatic fuel block) dan reaktor berpendingin gas helium dalam kenyataanya sekarang sudah ada dua macam, yaitu HTTR di Jepang yang berdaya 30 MWth dan HTR-10 di China dengan daya 10 MWth yang sama dengan RDE yang akan di bangun di Indonesia. Skema reaktor HTGR ditunjukkan oleh Gambar 2.

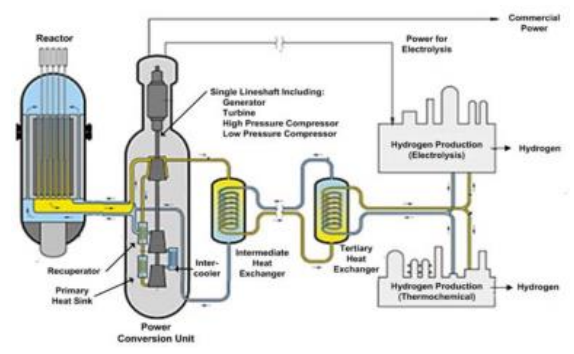

Gambar 2. Skema reaktor HTGR ${ }^{9}$.

\section{Bahan Bakar}

HTGR didesain dengan menggunakan bahan bakar keramik yang di suport oleh inherent safety dari HTGR. Bentuk bahan bakarnya disebut dengan TRISO $^{10}$. Bahan bakar tristructural-isotropic (TRISO) adalah jenis partikel bahan bakar mikro. TRISO terdiri dari kernel bahan bakar terbentuk dari UOX (Uranium Oxide) di tengahtengahnya ${ }^{11}$. Bahan bakar TRISO dilihat pada Gambar 3 berikut.

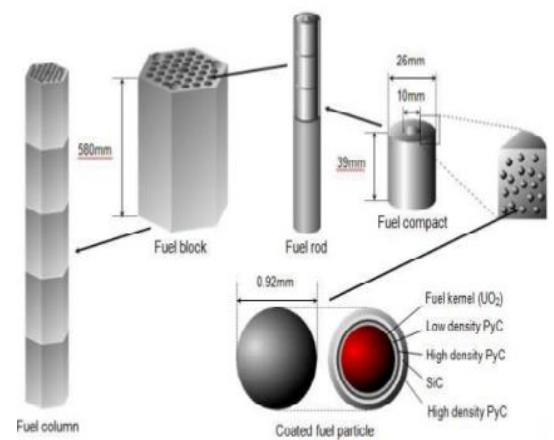

Gambar 3. Bahan bakar pada teras HTGR prismatic $^{10}$.

Lalu lapisan yang terdiri dari empat layer dari tiga material isotropik. Keempat lapisan adalah lapisan berpori penyangga yang terbuat dari karbon, diikuti oleh lapisan dalam padat karbon pirolitik (PyC), diikuti oleh lapisan keramik $\mathrm{SiC}$ untuk mempertahankan produk fisi pada temperatur tinggi ${ }^{10}$. 


\section{Reaktivitas}

Perubahan pada reaktivitas yang bisa bernilai positif maupun negatif adalah karena beberapa kejadian tidak sengaja maupun karena kesengajaan ${ }^{14}$. Diantara kejadiankejadian tersebut adalah penarikan CR, osilasi Xenon, pergerakan CR karena kesalahan pengukuran daya atau kesalahan operator, naik dan turunnya suhu penghilang panas primer secara tiba-tiba, pemadatan teras pebble bed karena gempa bumi, patahnya saluran pemindah panas pada steam generator atau penukar panas yang mengakibatkan air atau uap masuk ke dalam teras (densitas uap yang meningkat menyebabkan kesalahan nilai CR), jatuhnya $\mathrm{CR}$, kesalahan pemuatan bahan bakar, dan loncatnya CR keluar teras ${ }^{10}$.

\section{Batang Kendali (CR)}

Terdapat 16 pasang CR dalam teras HTTR dengan 7 pasang di tengah-tengah bahan bakar dan 9 pasang lainnya di bagian reflector $^{12}$ dengan skema yang ditunjukkan oleh Gambar 4 di bawah ini.

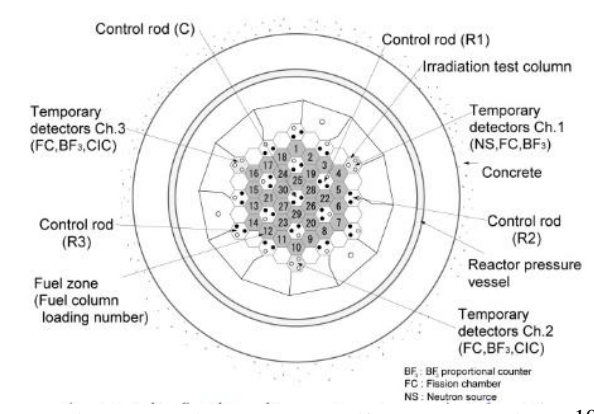

Gambar 4. Skema CR di teras reaktor ${ }^{10}$.

CR seperti pada Gambar 5 bisa mencapai kondisi subkritis dari semua kondisi operasi dan menjaga kondisi subkritis bahkan ketika ada sepasang CR yang macet dalam pengoperasiannya. Lalu ketika SCRAM pada kondisi operasi normal, CR pada bagian reflektor masuk ke dalam teras karena dilepaskan dari sistem penggerak dan sisanya dilepaskan ke teras setelah reaktor dingin dengan maksud agar CR tidak retak karena berada pada kondisi dengan suhu outlet $950{ }^{\circ} \mathrm{C}{ }^{8}$. Skema CR ketiak SCRAM bisa dilihat pada Gambar 6.

Selama operasi normal, posisi CR diatur dengan torsi motor dengan kecepatan maksimal adalah $70 \mathrm{~mm} / \mathrm{s}$. Ketika arus listrik melalui kopling elektromagnet, maka terjadilah sinyal SCRAM dan terpisahlah antar kopling (electromagentic clutch) dengan $\mathrm{CR}^{10}$.

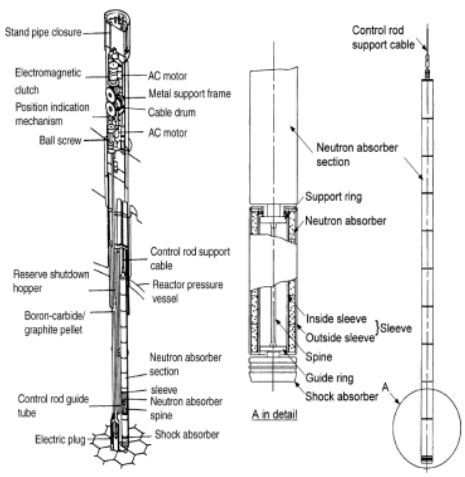

Gambar 5. CR pada HTTR ${ }^{10}$.

Untuk melindungi kabel pendukung CR dari beban penuh, rem pembatas kecepatan menjaga kecepatan CR tetap selama reaktor SCRAM dengan menggunakan pengatur torsi pada kecepatan tertentu. Mekanisme peredam benturan (shock absorber) mengurangi kecepatan CR pada posisi terbawah dengan gas ${ }^{10}$.

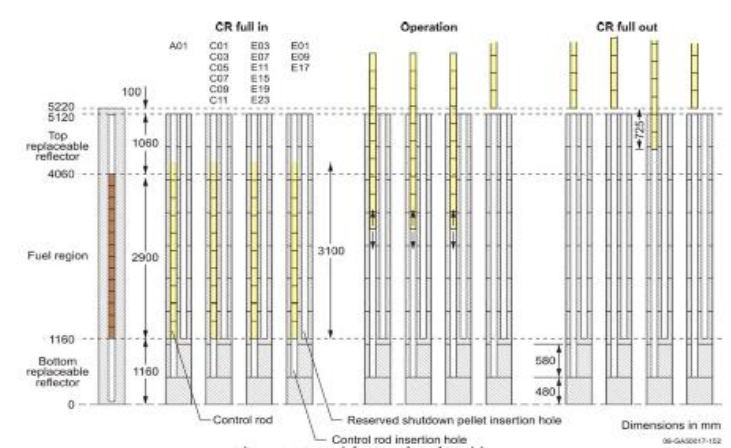

Gambar 6. Posisi $\mathrm{CR}^{10}$.

\section{Xenon}

Xenon adalah produk fisi yang menyerap neutron dan memiliki reaktivitas negatif atau biasa disebut Xenon Poisoning yang muncul kapan saja ketika reaktor sedang dalam operasi tingkat daya dengan waktu paro sekitar 11 jam. Pada kejadiannya, Xenon berasal dari dua sumber, yaitu dari produk fisi peluruhan dari Te-135 yang meluruh menjadi I-135 menjadi Xe-135 (Xenon) dan yang kedua adalah langsung dihasilkan dari proses fisi nuklir yang terjadi 
dan setelah 40 jam akan mencapai titik keseimbangan (equilibrium value $)^{13}$.

Titik keseimbangan ini dicapai ketika jumlah Xenon yang dihasilkan dan yang terbakar setara. Kemudian semakin tinggi tingkat dayanya, semakin tinggi juga titik keseimbangan Xenonnya, namun hal ini tidak selalu sebanging dengan tingkatan dayanya ${ }^{13}$. Sementara itu untuk kondisi Xenon setalah reaktor shutdown bisa dilihat pada Gambar 7 berikut ini.

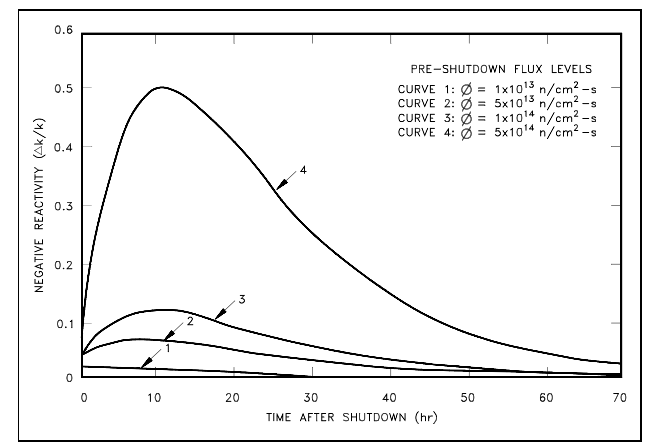

Gambar. Perubahan Xenon setelah reaktor shutdown ${ }^{13}$.

Ketika mengoperasikan reaktor, xenon merupakan salah satu hal yang dipertimbangkan karena memiliki sifat menyerap neutron dengan tampang lintang serap netron yang mencapai $2,65 \times 10^{6}$ barn. Adapun proses produk fisi menjadi Xenon hingga stabil bisa dilihat pada proses berikut ini $^{13}$.

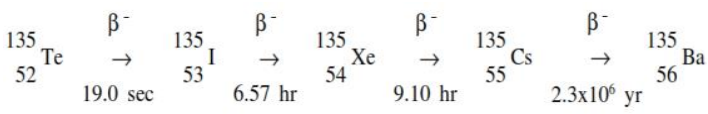

\section{METODE PENELITIAN}

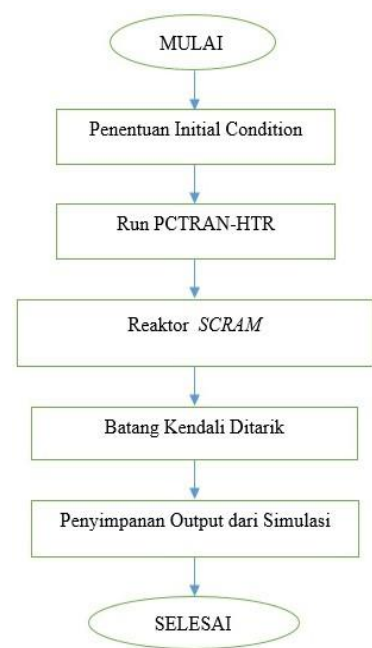

Gambar 7. Input data
Pada simulasi penarikan CR ini digunakan simulator PCTRAN-HTR 200 MWth dengan variasi daya $85 \%$ daya RDE, $70 \%, 85 \%$ dan $100 \%$ daya tinggi sebelum SCRAM terjadi. Pelaksanaan penelitian bisa dilihat pada Gambar 7 dan Gambar 8 di bawah ini.

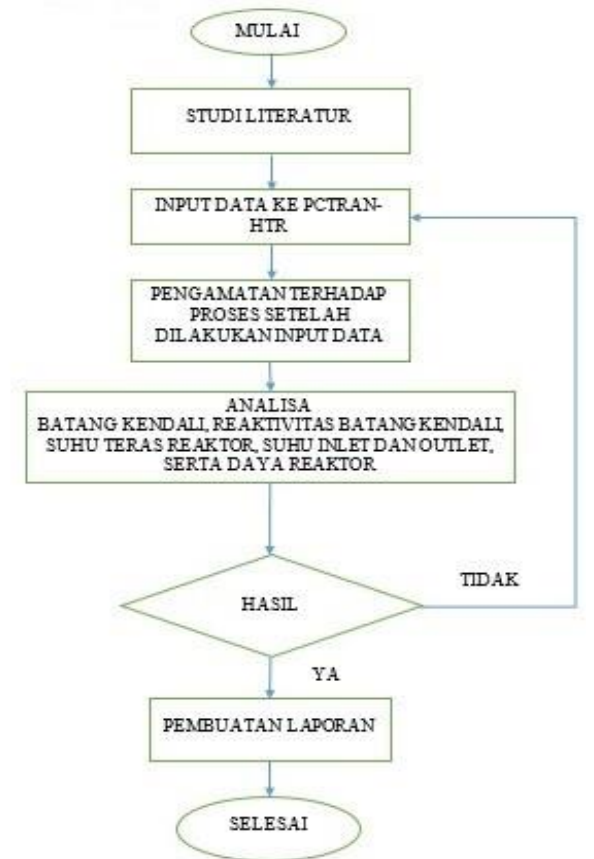

Gambar 8. Diagram alir penelitian.

Pada penelitian ini dilakukan pengoperasian reaktor dengan asumsi reaktor sudah dalam kondisi daya konstan (status $P O W E R$ ) dan semua kondisi normal kemudian terjadi SCRAM karena pasokan daya listrik ke sistem CR terputus beberapa saat sehingga CR jatuh. Untuk melanjutkan lagi perlu memperhatikan reaktivitas yang negatif terutama oleh reaktivitas Xe-135 yang memiliki umur 11,5 jam. Setelah SCRAM, maka status operasi reaktor adalah start (S) dan dilakukan penarikan CR pada posisi tertentu dengan kecepatan $6 \mathrm{~mm} / \mathrm{s}$ hingga teras menghasilkan fluks neutron yang cukup untuk menghasilkan daya dengan persentase $30 \%$. Kemudian status operasi reaktor diganti power $(\mathrm{P})$ dan terus dinaikkan hingga posisi yang dirasa daya menjadi steady state dengan total nilai reaktivitas reaktor posistif dan reaktivitas Xe-135 juga konstan (dalam grafik menjadi datar). Tahapan-tahapan skenario penelitian ini bisa dilihat pada Tabel 1. 
Tabel 1. Skenario Penelitian

\begin{tabular}{|c|c|c|c|c|c|c|}
\hline $\begin{array}{c}1 \\
\text { Daya } \\
(\%)\end{array}$ & 2 & Daya (\%) & 3 Reaktivitas & $\begin{array}{c}4 \\
\text { Penarikan } \\
\text { CR }\end{array}$ & $\begin{array}{c}5 \\
\text { Perubahan Status }\end{array}$ & $\begin{array}{c}6 \\
\text { Daya } \\
(\%)\end{array}$ \\
\hline 100 & $S$ & & & & & \\
\hline $\begin{array}{l}85 \\
70\end{array}$ & $\begin{array}{l}C \\
R \\
A\end{array}$ & $<2 \%$ & $\begin{array}{l}\text { Sangat } \\
\text { negatif }\end{array}$ & Posisi? & $\begin{array}{c}\text { Dari START } \\
\text { diubah ke } \\
\text { POWER bila daya }\end{array}$ & $\begin{array}{l}\text { Minimal } \\
\text { dan stabil }\end{array}$ \\
\hline $\begin{array}{c}85 \\
(\mathrm{RDE})\end{array}$ & M & & & & (3) $30 \%$ & \\
\hline
\end{tabular}

\section{HASIL DAN PEMBAHASAN}

Pada penelitian HTGR menggu-nakan simulator PCTRAN-HTR, daya dan waktu operasi sebelum SCRAM divaria-sikan dari $85 \%$ (RDE), $70 \%, 85 \%$ dan $100 \%$ dengan waktu varisi 50 detik, 10 ribu detik, dan 20 ribu detik. Maksud dari $85 \%$ (daya RDE) adalah selain melihat kondisi daya pada bagian sangat rendah dan juga sebagai penelitian pengembangan Reaktor Daya Eksperimental (RDE) 10 MWth di Indonesia. Adapun varisi daya dan waktu ini diharapkan bisa memberikan keakuratan dari penelitian ini yang berkaitan dengan penarikan batang kendali (CR) setelah SCRAM dengan memperhatikan reaktivitas-reaktivitas yang ada, khusunya Xenon, suhu dan CR.

Reaktivitas Xenon sangat terpengaruh oleh daya pada reaktor sebelum terjadinya $S C R A M$ dan pada penelitian ini diasumsikan bahwa kesetimbangan Xenon pada setiap variasi daya sebelum SCRAM adalah sama namun memiliki pengaruh dalam kelanjutan operasi reaktor setelah SCRAM dengan reaktivitasnya semakin negative bila daya sebelum SCRAM semakin tinggi.

\section{Daya RDE}

Nilai puncak Xenon hasil penelitian ini sesuai Gambar 8 adalah 1,17\% dk/k akibat SCRAM dari $85 \%$ daya RDE (untuk pengujian daya RDE). Selanjutnya untuk penarikan $\mathrm{CR}$, kondisi Xenon harus turun terlebih dahulu ke posisi $1,16 \% \mathrm{dk} / \mathrm{k}$ yang dicapai dengan waktu 11,7 jam dengan posisi CR 51\%, 52\%, 53\% dan 54\%.

Daya reaktor yang bisa dihasilkan dari proses penarikan CR setelah SCRAM pada reaktor HTGR dengan simulator PCTRANHTR terutama yang mengha- silkan daya di atas 30\% untuk daya RDE adalah CR dengan posisi mulai $52 \%$ seperti yang telihat pada Gambar 10. Adapun untuk posisi 51\% seperti yang ditunjukkan oleh Gambar 9 belum mampu mencapai daya lebih dari $30 \%$.

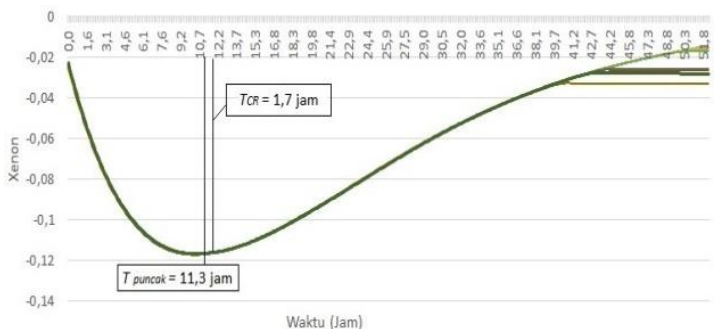

Gambar 8. Perubahan Xenon akibat SCRAM dari daya RDE

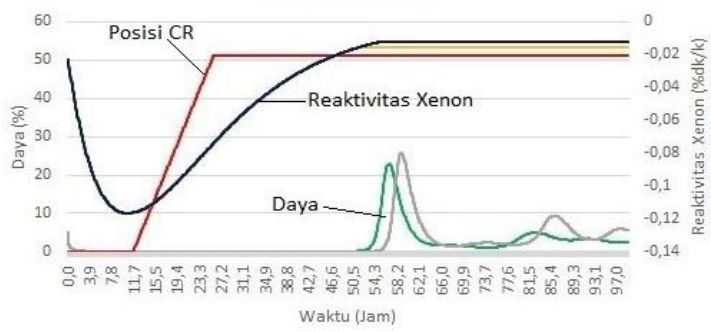

Gambar 9. Kenaikan daya dengan posisi CR $51 \%$

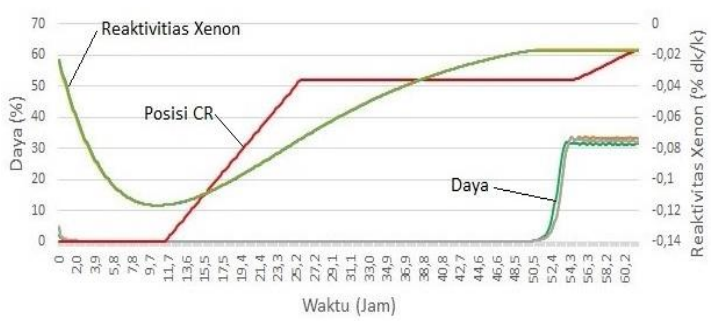

Gambar 10. Kenaikan daya dengan posisi CR $52 \%$

\section{Daya Tinggi}

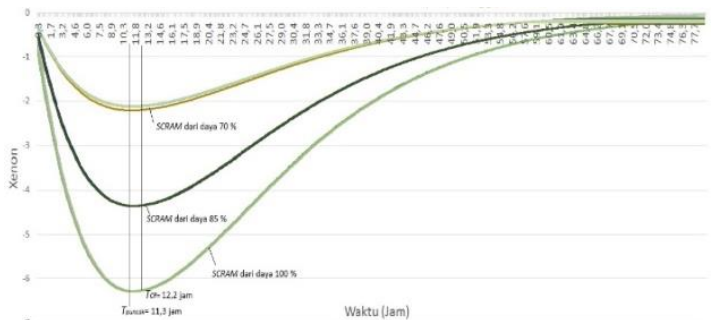

Gambar 11. Perubahan Xenon akibat SCRAM dari tinggi

Pada simulasi dengan daya tinggi nilai Xenonnya adalah $2,12 \% \mathrm{dk} / \mathrm{d}$ ketika SCRAM dari daya $70 \%, 4,35 \% \mathrm{dk} / \mathrm{d}$ pada daya $85 \%$ dan $6,28 \% \mathrm{dk} / \mathrm{d}$ pada daya $100 \%$ yang ditunjukkan oleh Gambar 1. Setelah kembali menurun jumlahnya, yaitu pada nilai $2,11 \%$ 
$\mathrm{dk} / \mathrm{k}, 4,34 \% \mathrm{dk} / \mathrm{k}$ dan 6,27 \% dk/k (12,2 jam setelah SCRAM), CR ditarik menuju posisi tertentu divariasikan dari $55 \%, 57 \%, 58 \%$, $59 \%, 60 \%$ dan $61 \%$.

\section{SCRAM dari daya $70 \%$}

Daya reaktor yang bisa dihasilkan dari proses penarikan CR setelah SCRAM dari daya $70 \%$ pada reaktor HTGR dengan simulator PCTRAN-HTR terutama yang mengha- silkan daya di atas $30 \%$ untuk daya tinggi adalah CR dengan posisi mulai $57 \%$ dan $58 \%$. Adapun untuk posisi $57 \%$ seperti yang ditunjukkan oleh Gambar 12 belum mampu mencapai daya lebih dari $30 \%$ dan baru bisa dicapai dengan posisi CR $58 \%$ seperti pada Gambar 13.

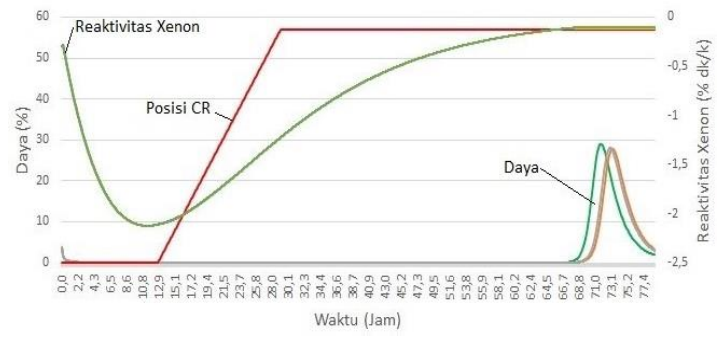

Gambar 12. Kenaikan daya dengan posisi CR $57 \%$

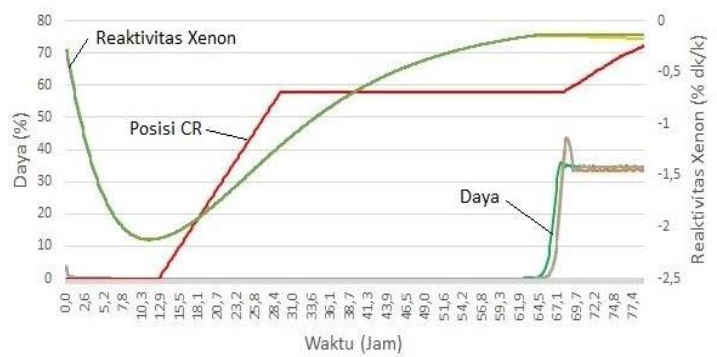

Gambar 13. Kenaikan daya dengan posisi CR $58 \%$

\section{SCRAM dari daya $85 \%$}

Setelah SCRAM dari daya $85 \%$, posisi $55 \%$ seperti yang ditunjukkan oleh Gambar 14 belum mampu mencapai daya lebih dari $30 \%$ dan baru bisa dicapai dengan posisi CR 57\% sesuai Gambar 15.

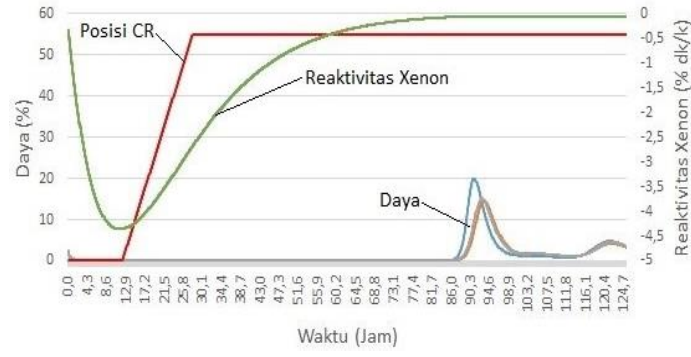

Gambar 14. Kenaikan daya dengan posisi CR $55 \%$

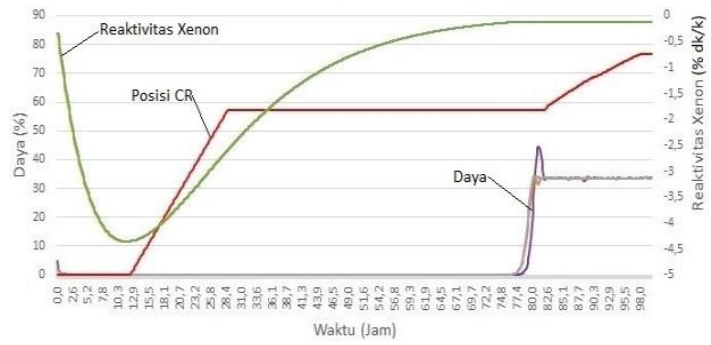

Gambar 15. Kenaikan daya dengan posisi CR $57 \%$

\section{SCRAM dari daya $100 \%$}

Sama dengan hasil setelah SCRAM dari daya $85 \%$. Pada kenaikan daya yang bisa lebih dari $30 \%$ setelah SCRAM dari daya $100 \%$ seperti pada Gambar 17, yaitu bisa dicapai dengan posisi CR $57 \%$. Sedangkan untuk posisi $55 \%$ belum mampu menghasilkan daya lebih dari $30 \%$ seperti yang ditampilkan pada Gambar 16.

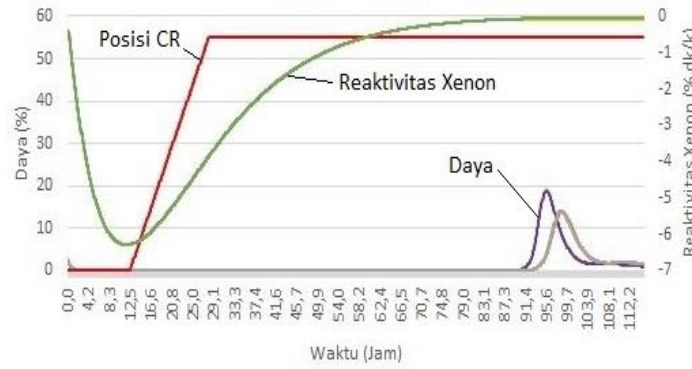

Gambar 16. Kenaikan daya dengan posisi CR $55 \%$

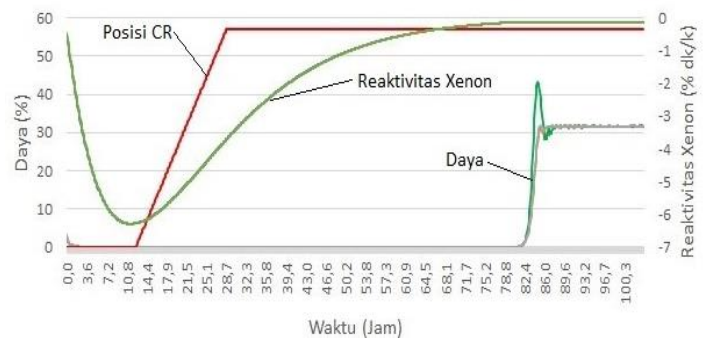

Gambar 17. Kenaikan daya dengan posisi CR $57 \%$ 


\section{Suhu}

Berkaitan dengan kenaikan CR dan perubahan suhu reaktor HTGR untuk daya RDE, dalam simulasi ini ternyata pada daya RDE dengan posisi CR $51 \%$ hingga CR 54 $\%$ membuat kenaikan suhu yang masih dalam batasan-batasan operasi dengan suhu inlet maupun outlet masih dibawah $950{ }^{\circ} \mathrm{C}$. Sedangkan untuk percobaan dengan daya tinggi. Hasil menunjukkan bahwa suhu outlet mencapai lebih dari $1000{ }^{\circ} \mathrm{C}$, namun hal itu masih dalam batasan aman.

\section{KESIMPULAN}

'Berdasarkan percobaan yang telah dilakukan menggunakan PCTRAN-HTR didapatkan posisi batang kendali yang optimal untuk percobaan daya RDE (10 MWth) adalah dengan posisi CR $52 \%$ dan untuk daya tinggi (200 MWth) adalah dengan posisi $58 \%$ untuk kondisi setelah SCRAM dari daya $70 \%$ dan posisi $57 \%$ untuk kondisi setelah SCRAM dari daya $85 \%$ dan $100 \%$. Sehingga dengan posisi CR tersebut status operasi sudah bisa diubah dari start (S) menjadi power $(\mathrm{P})$ dan dengan kenaikan batang kendali (CR) tersebut tidak terjadi suatu masalah seperti kenaikan suhu berlebihan sehingga menyebabkan reaktor SCRAM lagi.

\section{SARAN}

Saran yang diberikan agar penelitian selanjutnya bisa lebih baik dari penelitian ini adalah:

1. Perlu ditambakan variasi daya sebelum SCRAM sehingga semakin banyak data akan semakin menguatkan hasil yang diperoleh.

2. Untuk penelitian selanjutnya diharapkan melakukan penelitian mengenai batas atas posisi CR yang ditarik setelah Xenon mencapai puncaknya akibat SCRAM yang mana posisi CR masih memenuhi batasan-batasan operasi HTGR.

3. Perlu dilakukan penelitian dengan variasi waktu setelah reaktor SCRAM dan posisi CR tidak divariasikan sehingga diharapkan bisa diketahui pengaruh reaktivitas Xenon yang semakin menurun terhadap posisi CR yang sama.

\section{DAFTAR PUSTAKA}

1 Nakagawa, Sawa, Ohashi: Safety Analysis of Abnormal Reactivity Events in HTTR: JAERI. 1992

2 Chen, Dong, Zheng, Shi, Zhang: Benchmark Calculation for the SteadyState Temperature Distribution of the HTR-10 under Full-Power Operation. Beijing: Institute of Nuclear and New Energy Technology, Tsinghua University. 2008

3 Fujikawa, Hayashi, Nakazawa, Kawasaki, Nakagawa, Sakaba: Achievement of Reactor-Outlet Coolant Temperature of $950^{\circ} \mathrm{c}$. in HTTR. OaraiMachi: JAERI. 2004

4 Tachibana, Nishihara, Sakaba, Ohashi, Sato, Ueta, Aihara, Goto, Sumita, Shibata, Takamasu, Hamamoto, Inagaki, Iyoku, Kunitomi. Test Plan using the HTTR for Commercialization of GTHTR300C. In: JAEA Tech 2009-063. Oarao-machi: JAEA. 2009

5 Tachibana, Sawahata, Iyoku, Nakazawa. Reactivity Control System of the High Temperature Engineering Test Reactor. Oarai-Machi:ScienceDirect. 2004

6 JAEA. Confirm excellent and inherent safety characteristics of HTGR during an abnormal control rod withdrawal-News Release: JAEA (Diakses tanggal 12 Maret 2016).

7 Tochio, Watanabe, Motegi, Kawano, Kameyama, Sekita, Kozo. Operating Experience since Rise to Power Test in High Temperature Engineering Test Reactor (HTTR)-JAEA Technology 2007014. Shirakata Shirane: JAEA. 2007

8 Micro-Simulation Technology. PCTRAN HTR Simulator Software for PC. New Jersey. 2015

9 Takeda, Nakagawa, Honma, Takada, Fujimoto. Safety Shutdown of the High Temperature Engineering Test Reactor during Loss of Off-site Electric Power Simulation Test. Oarai-Machi:Taylor \& Francis. 2002.

10 Chapin. D, Kiffer. S, Nestell. J. The Very High Temperature Reactor: A Technical 
Summary", Alexandria: MPR Associates, Inc. 2004.

11 Bess. J. D, Sterbentz. J, Fujimoto. Evaluation of the Start-Up Core Physics Tests at Japan's High Temperature Engineering Test Reactor (Fully-Loaded Core). Idaho Falls: Idaho National Laboratory. 2009

12 IAEA. Evaluation of high temperature gas cooled reactor performance: Benchmark analysis related to initial testing of the HTTR and HTR-10 IAEATECDOC-1382, Vienna: IAEA. 2003

13 Tachibana, Sawahata, Iyoku, Nakazawa. Test Plan using the HTTR for Commercialization of GTHTR300C. Ibaraki: JAEA. 2004

14 DOE-HDBK-1019/2-93. Fundamentals Handbook Nuclear Physics and Reactor Theory Volume 2 of 2. Washington D.C.: U.S. Department of Energy. 1993

15 Ball, S. J. Overview of Modular HTGR Safety Characterization and Postulated Accident Behavior Licensing Srategy. Oak Ridge: Oak Tidge National Laboratory. 2014 
Jurnal Forum Nuklir (JFN) Volume 13, Nomor 2, November 2019 